\title{
The prenylation inhibitor manumycin $A$ reduces the viability of Anaplasma phagocytophilum
}

\author{
Qingming Xiong and Yasuko Rikihisa
}

Correspondence

Yasuko Rikihisa

rikihisa.1@osu.edu

Received 18 December 2010

Accepted 23 February 2011
Department of Veterinary Biosciences, College of Veterinary Medicine, The Ohio State University, 1925 Coffey Road, Columbus, OH 43210, USA

\begin{abstract}
Anaplasma phagocytophilum is an obligately intracellular bacterium and is the causative agent of human granulocytic anaplasmosis (HGA), an emerging and major tick-borne disease in the USA and other parts of the world. This study showed that the prenylation inhibitor manumycin $\mathrm{A}$ effectively blocked $A$. phagocytophilum infection in host cells (HL-60 or RF/6A cells).

A. phagocytophilum infection activated extracellular signal-regulated kinase (ERK) mitogen-activated protein kinase in host cells, and manumycin A treatment reduced ERK activation in $A$. phagocytophilum-infected host cells. As ERK activation is required for $A$. phagocytophilum infection, we examined whether manumycin A inhibited the bacteria directly or through host ERK signalling. Treatment of $A$. phagocytophilum alone with manumycin $\mathrm{A}$ significantly reduced the bacterial infectivity of host cells and bacterial viability in the absence of host cells, whereas pre-treatment of host cells did not inhibit bacterial infection in host cells. The inhibitory effect of manumycin A on $A$. phagocytophilum infection in host cells was achieved even at a concentration 100 times lower than that required for effective inhibition of mammalian cell signalling. These results suggested that manumycin A directly inactivates the bacterium, resulting in reduced infection and ERK1/2 activation. Thus, the manumycin group of drugs may have a therapeutic potential for HGA.
\end{abstract}

\section{INTRODUCTION}

Anaplasma phagocytophilum is a tick-borne Gram-negative bacterium that proliferates in membrane-bound inclusions in granulocytes and endothelial cells of various mammalian species (Dumler et al., 2001; Goodman et al., 1996; Munderloh et al., 2004). In humans, A. phagocytophilum causes human granulocytic anaplasmosis (HGA), an emerging and major tick-borne disease in the USA and other parts of the world. Since it was first identified in the early 1990s in a Wisconsin patient who died from a severe febrile illness after a tick bite (Chen et al., 1994), HGA has been increasingly recognized in North America, Europe and Asia as a cause of an acute and severe febrile disease after a tick bite (Bakken \& Dumler, 2008; Parkins et al., 2009; Zhang et al., 2008). HGA is often accompanied by headache, myalgia and malaise. Severe complications include prolonged fever, shock, confusion, acute renal failure, haemorrhage, rhabdomyolysis, opportunistic infection by viral and fungal agents, and even death when diagnosis and treatment are delayed (Bakken \& Dumler, 2008). The outcome of HGA is poor in elderly or immunocompromised individuals (Bakken \& Dumler,

Abbreviations: ERK, extracellular signal-regulated kinase; HGA, human granulocytic anaplasmosis; $I_{50}, 50 \%$ inhibition concentration; p.i., post-inoculation.
2000). The number of reported anaplasmosis cases has increased every year since this disease was selected as one that should be notified to the Centers for Disease Control and Prevention in 1999. Compared with 2007, the number of cases attributed to A. phagocytophilum in 2008 had increased by $21 \%$ (Hall-Baker et al., 2010). In the recent summary of notifiable diseases in the USA during 2009, 1161 cases of HGA were reported (CDC, 2010).

Because of the potential for severe and fatal disease, chemotherapy is indicated for all suspected or confirmed HGA cases. The drug of choice is a tetracycline antibiotic, usually doxycycline, as A. phagocytophilum is highly susceptible to doxycycline. If there is no significant treatment delay, the response to doxycycline is usually very rapid, with improvement evident within 24-48 h (Bakken \& Dumler, 2008). Although tetracycline-based drugs are generally effective in treating A. phagocytophilum infection, therapies for children and pregnant women are still urgently needed because of the side effects of tetracycline (Korzeniowski, 1995; Lochary et al., 1998). Rifampicin and the new fluoroquinolone antibiotic trovafloxacin are effective in vitro (Horowitz et al., 2001; Klein et al., 1997), but limited in vivo studies are available to confirm the in vitro data (Buitrago et al., 1998; Krause et al., 2003). Therefore, rifampicin is recommended only for patients with contraindications to doxycycline or tetracycline therapy (Bakken \& Dumler, 
2008). Currently, no other therapeutic drugs are available for HGA treatment.

A. phagocytophilum resides and proliferates in the professional killer cells of the host and disrupts many cell functions, in particular by modulating host-cell signalling to benefit itself and establish infection in the host (Rikihisa, 2003, 2006). It has been shown that $A$. phagocytophilum activates extracellular signal-regulated kinase (ERK) in neutrophils and HL-60 cells (Lee et al., 2008; Sukumaran et al., 2011; Xiong et al., 2009) and that ERK activation is required for $A$. phagocytophilum infection (Xiong et al., 2009). One of the best-characterized ERK activation pathways is Ras/Raf/MEK/ ERK (Roux \& Blenis, 2004), and manumycin A, a farnesyltransferase inhibitor, is known to inhibit this pathway by inhibiting Ras farnesylation (Ito et al., 1996). The aim of this study was to determine the effects of manumycin A on the growth of $A$. phagocytophilum in mammalian host cells and the potential mechanism of this inhibitory effect.

\section{METHODS}

Reagents and antibodies. Manumycin A was purchased from Calbiochem. Mouse mAb 5C11, which recognizes the $\mathrm{N}$-terminal conserved region of the A. phagocytophilum major surface protein P44, has been described previously (Kim \& Rikihisa, 1998). Other antibodies used were mouse mAb against phospho-ERK1/2 (E10; Cell Signaling), rabbit anti-ERK1/2 (Cell Signaling) and mouse $\mathrm{mAb}$ against $\alpha$-tubulin (Santa Cruz Biotechnology). Peroxidase-conjugated secondary antibodies were obtained from KPL.

A. phagocytophilum culture and manumycin A treatments. The A. phagocytophilum HZ strain was cultivated in the human promyelocytic leukaemia cell line HL-60 (Rikihisa et al., 1997). Host-cell-free A. phagocytophilum was prepared by sonicating highly infected ( $>90 \%$ infected) HL-60 cells for $8 \mathrm{~s}$ twice at an output setting of 2 with an ultrasonic processor (W-380; Heat Systems). After low-speed centrifugation at $500 \mathrm{~g}$ for $5 \mathrm{~min}$ to remove nuclei and unbroken cells, the supernatant was centrifuged at $10000 \mathrm{~g}$ for $10 \mathrm{~min}$ and the pellet, which was enriched with host-cell-free organisms, was added to HL-60 or endothelial RF/6A cells. After $2 \mathrm{~h}$ incubation at $37^{\circ} \mathrm{C}$, extracellular organisms were washed, fresh medium was added and this time point was considered $0 \mathrm{~h}$ postinoculation (p.i.). Cells continued to be incubated at $37^{\circ} \mathrm{C}$.

Manumycin A was added before infection (pre-treatment) or at indicated time points ( $0 \mathrm{~h}$ or 1 day p.i.) and the inhibitor was kept in the growth medium throughout the incubation period or was removed later as indicated. Inhibitor treatments at these concentrations did not affect host-cell integrity as assessed by light microscopy and trypan blue staining. The degree of bacterial infection in host cells was assessed by Diff-Quik staining (Baxter Scientific Products) and (a)

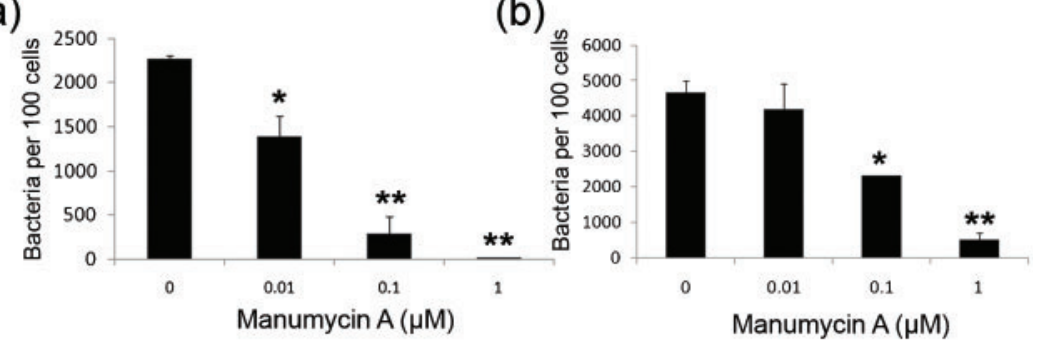

(c)

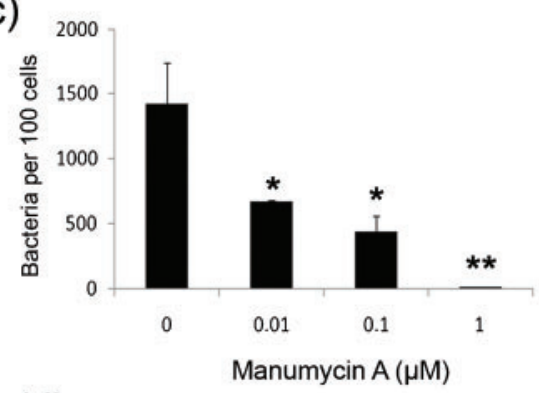

(d)

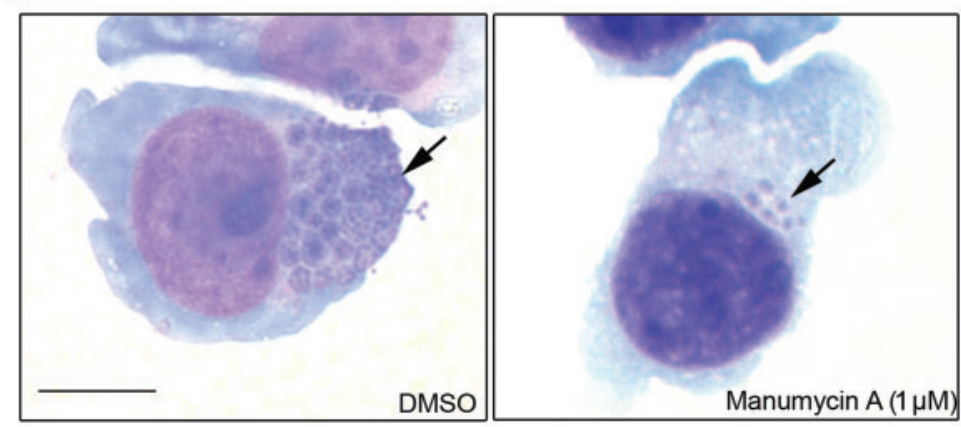

Fig. 1. Manumycin A blocks A. phagocytophilum infection in host cells. Manumycin A $(0,0.01,0.1$ and $1 \mu \mathrm{M}$ in $1 \%$ DMSO) was added to HL-60 cells $(a, b)$ or RF/6A cells (c) at $0 \mathrm{~h}$ p.i. $(\mathrm{a}, \mathrm{c})$ or 1 day p.i. $(b, d)$. The number of bacteria was determined at 2 days p.i. $(a, b)$ or 3 days p.i. (c). Data are expressed as means $\pm \mathrm{SD}(n=3)$ and are representative of three independent experiments with similar results. * $P<0.05 ;{ }^{* *}, P<0.01$ (unpaired twotailed $t$-tests). (d) At 2 days p.i., infected cells treated with $1 \mu \mathrm{M}$ manumycin $\mathrm{A}$ and vehiclecontrol DMSO were harvested and observed by light microscopy following Diff-Quik staining. Arrows indicate A. phagocytophilum inclusions. Note the much smaller inclusions, which contained fewer bacteria, in the manumycin Atreated cell compared with the control DMSOtreated cell. Bar, $5 \mu \mathrm{m}$. 
the number of A. phagocytophilum cells was estimated in 200 host cells in triplicate culture wells (Rikihisa et al., 1995).

Western blot analysis. A. phagocytophilum-infected and uninfected HL-60 cells $\left(1 \times 10^{6}\right)$ were washed, resuspended in $200 \mu \mathrm{l}$ ice-cold RIPA buffer (50 mM Tris/HCl, pH 7.4; $1 \%$ NP-40; $0.25 \%$ sodium deoxycholate; $150 \mathrm{mM} \mathrm{NaCl} ; 1 \mathrm{mM}$ EDTA) containing freshly added Protease Inhibitor Cocktail Set III and Phosphatase Inhibitor Cocktail Set II (Calbiochem) and lysed by mixing with $200 \mu \mathrm{l} 2 \times$ Laemmli sample buffer (135 mM Tris/HCl, pH 6.8; $4 \%$ SDS; $20 \%$ glycerol; $10 \% \beta$-mercaptoethanol). Samples were separated by SDS-PAGE on 7.5 or $10 \%$ polyacrylamide gels and then transferred to a nitrocellulose membrane with a semi-dry blotter (WEP). The membrane was blocked with $5 \%(\mathrm{w} / \mathrm{v})$ skimmed milk (BD) in Tris-buffered saline $(50 \mathrm{mM}$ Tris/ $\mathrm{HCl}, \mathrm{pH} 7.5 ; 150 \mathrm{mM} \mathrm{NaCl})$ containing $0.1 \%$ Tween 20 , incubated with primary antibodies (diluted $1: 500$ or $1: 1000$ ) at $4{ }^{\circ} \mathrm{C}$ for $12 \mathrm{~h}$ and subsequently incubated with peroxidase-conjugated secondary antibodies (diluted $1: 1000$ ) at room temperature for $1 \mathrm{~h}$. Immunoreactive bands were visualized with enhanced chemiluminescence (Thermo Scientific) using a CCD camera (Fuji LAS-3000 Imaging System) and band density was measured using Fujifilm MultiGauge software.

Immunofluorescence assay and live/dead bacterial staining. Host-cell-free A. phagocytophilum was filtered through a $2.7 \mu \mathrm{m}$ filter and pre-treated with manumycin $\mathrm{A}(1 \mu \mathrm{M})$ for $15 \mathrm{~min}$ in SPK buffer (0.05 M potassium phosphate, $\mathrm{pH}$ 7.4; $0.2 \mathrm{M}$ sucrose), followed by staining for 15 min with a LIVE/DEAD BacLight Bacterial Viability kit (Molecular Probes, Invitrogen). Cells were then mounted on slides and observed under a Nikon Eclipse E400 fluorescence microscope with a xenon/mercury light source (Nikon Instruments).

Statistical analysis. Statistical analyses were performed with unpaired, two-tailed Student's $t$-tests using Microsoft Office Excel. A value of $P<0.05$ was considered to be significant.

\section{RESULTS}

\section{Manumycin A blocks A. phagocytophilum infection in HL-60 and RF/6A cells}

We and others have shown previously that ERK signalling is highly activated in A. phagocytophilum-infected HL-60 cells and neutrophils (Lee et al., 2008; Xiong et al., 2009).
Because Ras/Raf/ERK are components of the major canonical mitogen-activated protein kinase activation pathway, we used the Ras prenylation inhibitor manumycin A to determine whether Ras is upstream of the cascade of ERK signalling induced by $A$. phagocytophilum infection in host cells. Manumycin A effectively blocked A. phagocytophilum infection in HL-60 cells in a dosedependent manner when manumycin A was added to the cell culture at 0 h p.i. (Fig. 1a). Significant inhibition was achieved at a concentration as low as $0.01 \mu \mathrm{M}$ (Fig. 1a). In addition, the inhibitory effect of manumycin A was still observed if the drug was added to the cell culture at 1 day p.i. (around $40 \%$ infected) (Fig. 1b). The bacteria in HL-60 cells were cleared by manumycin A treatment at a dosage of $1 \mu \mathrm{M}$. The A. phagocytophilum inclusions became smaller and looser in manumycin A-treated HL-60 cells (Fig. 1d). Similar experiments were carried out in the endothelial cell line RF/6A, which can be infected with A. phagocytophilum (Munderloh et al., 2004), and the same results were found (Fig. 1c).

\section{Manumycin A blocks ERK activation induced by $\boldsymbol{A}$. phagocytophilum infection in HL-60 cells}

Because our previous data showed that ERK activation is required for $A$. phagocytophilum infection (Xiong et al., 2009), we examined whether the reduced A. phagocytophilum infection was due to abolished ERK activation by manumycin A. Manumycin A blocked A. phagocytophilum infection (indicated by the relative protein levels of the A. phagocytophilum major surface protein P44) as well as ERK activation (indicated by the relative levels of phosphorylated ERK1/2) in HL-60 cells (Fig. 2).

\section{Pre-treatment of $A$. phagocytophilum with manumycin A abolishes $A$. phagocytophilum infection in HL-60 cells}

Manumycin A is a potent and selective eukaryotic farnesyltransferase inhibitor with a $50 \%$ inhibition concentration

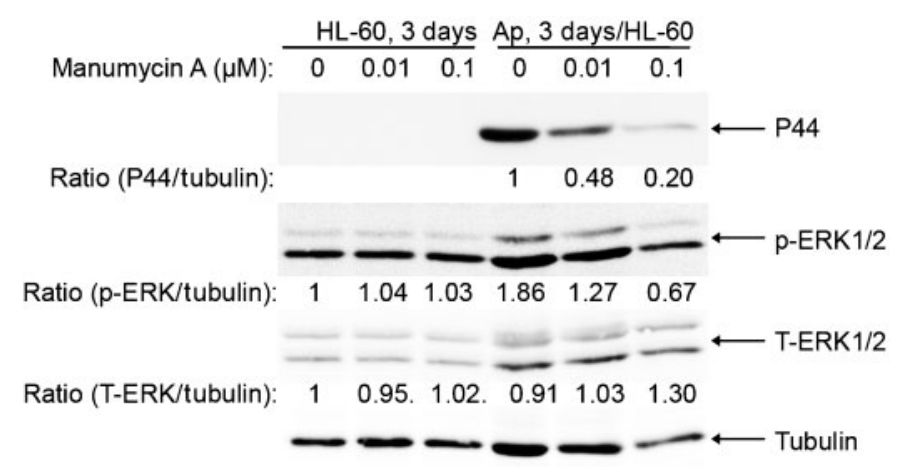

Fig. 2. A. phagocytophilum infection activates ERK and manumycin $A$ inhibits both bacterial infection and ERK activation in infected HL-60 cells. Western blot analysis was performed with antibodies specific to phosphorylated ERK (p-ERK), total ERK1/2 and P44, the A. phagocytophilum major surface protein. Uninfected and $A$. phagocytophilum-infected $\mathrm{HL}-60$ cells (Ap) with or without manumycin A treatment were collected at 3 days p.i. $\alpha$-Tubulin was used as a protein loading control to normalize each sample. The values under the bands show the ratios of band intensities of P44, p-ERK1/2 and total ERK (T-ERK) to $\alpha$-tubulin, respectively. Data are representative of three independent experiments. 
(a)

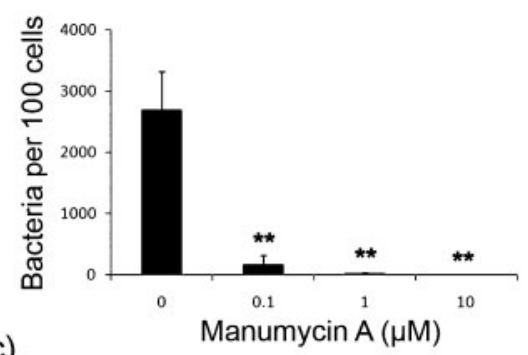

(c) (b)

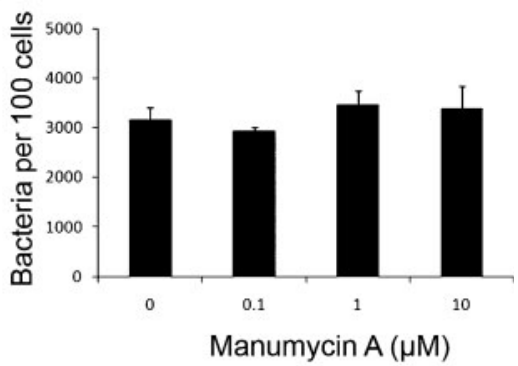

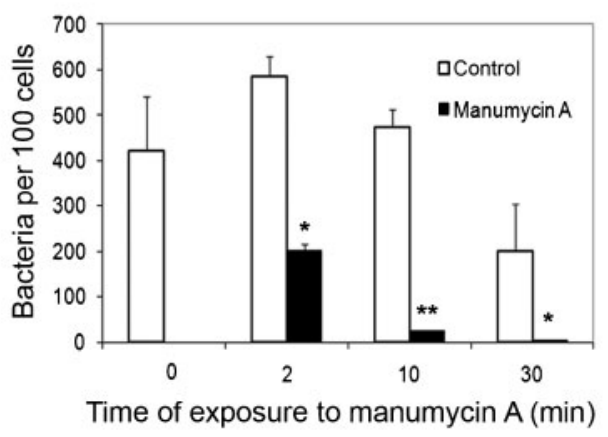

Fig. 3. Pre-treatment of $A$. phagocytophilum alone with manumycin $\mathrm{A}$ inhibits bacterial infection in host cells. (a) Host-cell-free A. phagocytophilum was pre-treated with serially diluted manumycin A for 15 min at $37{ }^{\circ} \mathrm{C}$ in SPK buffer and, after washing, was inoculated onto non-treated HL-60 cells. ${ }^{* *}, P<0.01$ (unpaired two-tailed $t$-test). (b) Host HL-60 cells were pre-treated with serially diluted manumycin $\mathrm{A}$ in RPMl for $15 \mathrm{~min}$ at $37{ }^{\circ} \mathrm{C}$. After washing, they were inoculated with non-treated $A$. phagocytophilum. The number of bacteria was determined at 2 days p.i. (c) Host-cell-free $A$. phagocytophilum was pre-treated with $1 \mu \mathrm{M}$ manumycin A or $1 \% \mathrm{DMSO}$ (control) for different time periods (2, 10 and $30 \mathrm{~min})$ at $37{ }^{\circ} \mathrm{C}$ in SPK buffer. A time of 0 min indicates cells that were not exposed to manumycin A or DMSO. After washing, the cells were inoculated onto $\mathrm{HL}-60$ cells. The number of bacteria was determined at 2 days p.i. Data are expressed as means $\pm \mathrm{SD}(n=3)$ and are representative of three independent experiments with similar results. ${ }^{*}, P<0.05 ;{ }^{*}, P<0.01$ (unpaired two-tailed $t$-tests). $P$ values were calculated for manumycin A-treated versus vehicle control for each time point.

$\left(\mathrm{IC}_{50}\right)$ of $5 \mu \mathrm{M}$ (Hara et al., 1993), which is much higher than the concentration $(<0.1 \mu \mathrm{M})$ used in our study to block A. phagocytophilum growth. This discrepancy led us to speculate that the reduced $A$. phagocytophilum infection in host cells may be due to manumycin A targeting the bacterium itself. To test this possibility, we pre-treated $A$. phagocytophilum with manumycin A and then infected host cells after removal of the drug by washing. Treatment of
A. phagocytophilum with manumycin A significantly accelerated the loss of infectivity in a dose- and time-dependent manner (Fig. 3a, c). In addition, this inactivation of $A$. phagocytophilum was highly effective, as only $2 \mathrm{~min}$ of treatment with manumycin $\mathrm{A}(1 \mu \mathrm{M})$ resulted in a significant reduction in bacterial infectivity (Fig. 3c). In contrast, the infectivity of $A$. phagocytophilum was not different when host HL-60 cells were pre-treated with manumycin A (Fig. 3b).

\section{DMSO}

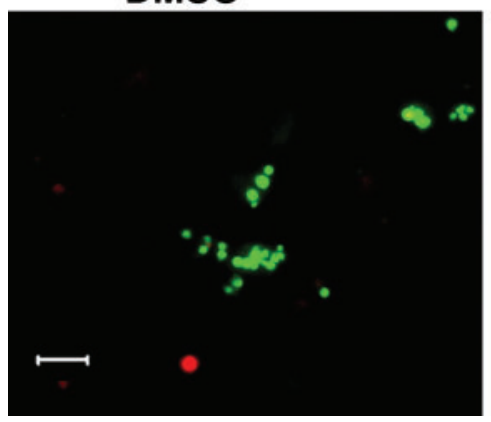

\section{Manumycin A}

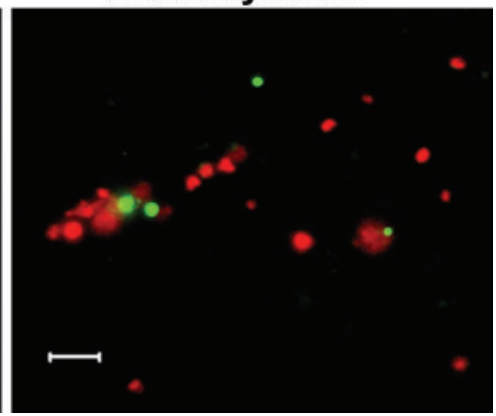

Fig. 4. Manumycin $\mathrm{A}$ reduces isolated $A$. phagocytophilum viability. Host-cell-free $A$. phagocytophilum was pre-treated with $1 \mu \mathrm{M}$ manumycin A or $1 \%$ DMSO for 15 min in SPK buffer, followed by staining for 15 min with the LIVE/DEAD BacLight Bacterial Viability kit, and was observed by fluorescence microscopy. A green signal indicates viable bacteria and a red signal indicates dead bacteria. Data are representative of three independent experiments with similar results. Bars, $5 \mu \mathrm{m}$. 


\section{Manumycin A reduces $A$. phagocytophilum viability in the absence of host cells}

Because A. phagocytophilum pre-treatment with manumycin A caused a significant reduction in bacterial growth in host cells, we examined bacterial viability after manumycin A treatment with the LIVE/DEAD BacLight Bacterial Viability kit. Over 200 total green (live) or red (dead) bacteria from different randomly selected fields as shown in Fig. 4 were scored. The percentage of live A. phagocytophilum in the manumycin A-treated group was $24.3 \pm 2.0 \%$, which is significantly lower than $78.2 \pm 2.1 \%$ in the control group $(n=3, P<0.01)$.

\section{DISCUSSION}

In this study, we demonstrated that A. phagocytophilum infection in host cells was effectively blocked by manumycin $A$ and that this inhibitory effect was due to the antimicrobial effect of manumycin A on the bacteria. To our knowledge, this is the first report of biological activity of manumycin against Gram-negative bacteria.

We showed previously that the cholesterol biosynthesis inhibitor lovastatin does not block but rather enhances $A$. phagocytophilum growth in culture (Xiong et al., 2009). Because both cholesterol and farnesylated-pyrophosphate are derived from the mevalonate pathway, lovastatin not only blocks de novo cholesterol synthesis but also blocks the synthesis of farnesylated-pyrophosphate, which is used in Ras prenylation on the membrane (Murthy et al., 2005). Our in vitro lovastatin data suggested that Ras prenylation may not be involved in A. phagocytophilum infection. This was puzzling at first for us, as the Ras farnesylation inhibitor manumycin A had strong inhibitory effects on ERK activated by $A$. phagocytophilum infection. Our current data showing that manumycin A has a direct effect on A. phagocytophilum solved this conundrum. Therefore, A. phagocytophilum infection may activate ERK in an alternative pathway. Recently, an A. phagocytophilum virulence protein, AptA, was identified as being involved in the activation of ERK1/2 during A. phagocytophilum infection (Sukumaran et al., 2011).

Manumycin A has been tested as an anti-cancer treatment in thyroid carcinoma, but concern was raised because of its toxicity in vitro and in animal models (Xu et al., 2001; Yeung et al., 2000). The $\mathrm{IC}_{50}$ of manumycin against yeast farnesyltransferase is $5 \mu \mathrm{M}$ (Hara et al., 1993). Manumycin A was shown to reduce the viability of all six human anaplastic thyroid cancer cell lines tested at concentrations of over $5 \mu \mathrm{M}$; however, manumycin A also inhibited the proliferation and viability of endothelial cells at concentrations of $2 \mu \mathrm{M}$ (Xu et al., 2001; Yeung et al., 2000). Below $1 \mu \mathrm{M}$, manumycin A has no inhibitory effects on mammalian cells (Xu et al., 2001; Yeung et al., 2000). The optimal concentration of manumycin A found in our study to block A. phagocytophilum infection in host cells was $0.1 \mu \mathrm{M}$, and in fact the inhibitory effect could be achieved at a concentration as low as $0.01 \mu \mathrm{M}$, which is 100 times lower than the concentration used for anti-cancer studies. This difference indicates that $A$. phagocytophilum is highly sensitive to manumycin A treatment and this inhibitory effect is not dependent on inhibition of host-cell signalling.

There are only a few reports about the antimicrobial activity of manumycin A. Because manumycin A has antiGram-positive bacterial activity in vitro, manumycin class antibiotics including U-62162 $\left(8 \mathrm{mg} \mathrm{kg}^{-1}\right)$ and U-56,407 $\left(320 \mathrm{mg} \mathrm{kg}^{-1}\right.$ ) have been tested in mice that were experimentally infected with Staphylococcus aureus (Brodasky et al., 1983; Slechta et al., 1982). Ali et al. (1999) reported that manumycin $\mathrm{A}$ is a sensitive and novel trypanocide in vitro $\left(\mathrm{IC}_{50}\right.$ values against two Trypanosoma brucei strains, BSF and PCF, were 1.5 and $0.4 \mu \mathrm{M}$, respectively), because it alters protein prenylation in $T$. brucei and causes mitochondrial damage. The biosynthesis of manumycin group compounds has been studied intensively and new analogues can be produced by manipulating the biosynthetic pathways such as by feeding artificial precursors or changing the cultivation parameters by increasing oxygen partial pressure (Sattler et al., 1998). Thus, in light of the extremely high sensitivity of $A$. phagocytophilum to manumycin $\mathrm{A}$, it is worth testing these new manumycin derivatives or other farnesyltransferase inhibitors for $A$. phagocytophilum inhibition in vitro and in vivo in the future. A. phagocytophilum has diverse host animal specificity, several genes are known to be variable among strains and potentially cell culture passage numbers may alter bacterial virulence (Dumler et al., 2001; Pusterla et al., 2000; Rikihisa et al., 2010; Scharf et al., 2011); therefore, it will also be prudent to examine these variable factors in the future.

\section{ACKNOWLEDGEMENTS}

This research was supported by NIH grant R01 AI30010.

\section{REFERENCES}

Ali, B. R., Pal, A., Croft, S. L., Taylor, R. J. \& Field, M. C. (1999). The farnesyltransferase inhibitor manumycin $\mathrm{A}$ is a novel trypanocide with a complex mode of action including major effects on mitochondria. Mol Biochem Parasitol 104, 67-80.

Bakken, J. S. \& Dumler, J. S. (2000). Human granulocytic ehrlichiosis. Clin Infect Dis 31, 554-560.

Bakken, J. S. \& Dumler, S. (2008). Human granulocytic anaplasmosis. Infect Dis Clin North Am 22, 433-448, viii.

Brodasky, T. F., Stroman, D. W., Dietz, A. \& Mizsak, S. (1983). U-56,407, a new antibiotic related to asukamycin: isolation and characterization. J Antibiot (Tokyo) 36, 950-956.

Buitrago, M. I., Ijdo, J. W., Rinaudo, P., Simon, H., Copel, J., Gadbaw, J., Heimer, R., Fikrig, E. \& Bia, F. J. (1998). Human granulocytic ehrlichiosis during pregnancy treated successfully with rifampin. Clin Infect Dis 27, 213-215.

CDC (2010). Summary of notifiable diseases, United States, 2009. MMWR 59, 1031. 
Chen, S. M., Dumler, J. S., Bakken, J. S. \& Walker, D. H. (1994) Identification of a granulocytotropic Ehrlichia species as the etiologic agent of human disease. J Clin Microbiol 32, 589-595.

Dumler, J. S., Barbet, A. F., Bekker, C. P., Dasch, G. A., Palmer, G. H., Ray, S. C., Rikihisa, Y. \& Rurangirwa, F. R. (2001). Reorganization of genera in the families Rickettsiaceae and Anaplasmataceae in the order Rickettsiales: unification of some species of Ehrlichia with Anaplasma, Cowdria with Ehrlichia and Ehrlichia with Neorickettsia, descriptions of six new species combinations and designation of Ehrlichia equi and 'HGE agent' as subjective synonyms of Ehrlichia phagocytophila. Int J Syst Evol Microbiol 51, 2145-2165.

Goodman, J. L., Nelson, C., Vitale, B., Madigan, J. E., Dumler, J. S., Kurtti, T. J. \& Munderloh, U. G. (1996). Direct cultivation of the causative agent of human granulocytic ehrlichiosis. N Engl J Med 334, 209-215.

Hall-Baker, P. A., Nieves, E., Jajosky, R. A., Adams, D. A., Sharp, P., Anderson, W. J., Aponte, J. J., Aranas, A. E., Katz, S. B. \& other authors (2010). Summary of notifiable diseases - United States, 2008. MMWR 57, 1-94.

Hara, M., Akasaka, K., Akinaga, S., Okabe, M., Nakano, H., Gomez, R., Wood, D., Uh, M. \& Tamanoi, F. (1993). Identification of Ras farnesyltransferase inhibitors by microbial screening. Proc Natl Acad Sci U S A 90, 2281-2285.

Horowitz, H. W., Hsieh, T. C., Aguero-Rosenfeld, M. E., Kalantarpour, F., Chowdhury, I., Wormser, G. P. \& Wu, J. M. (2001). Antimicrobial susceptibility of Ehrlichia phagocytophila. Antimicrob Agents Chemother 45, 786-788

Ito, T., Kawata, S., Tamura, S., Igura, T., Nagase, T., Miyagawa, J. I., Yamazaki, E., Ishiguro, H. \& Matasuzawa, Y. (1996). Suppression of human pancreatic cancer growth in $\mathrm{BALB} / \mathrm{c}$ nude mice by manumycin, a farnesyl:protein transferase inhibitor. Jpn J Cancer Res 87, 113-116.

Kim, H.-Y. \& Rikihisa, Y. (1998). Characterization of monoclonal antibodies to the 44-kilodalton major outer membrane protein of the human granulocytic ehrlichiosis agent. J Clin Microbiol 36, 32783284 .

Klein, M. B., Nelson, C. M. \& Goodman, J. L. (1997). Antibiotic susceptibility of the newly cultivated agent of human granulocytic ehrlichiosis: promising activity of quinolones and rifamycins. Antimicrob Agents Chemother 41, 76-79.

Korzeniowski, O. M. (1995). Antibacterial agents in pregnancy. Infect Dis Clin North Am 9, 639-651.

Krause, P. J., Corrow, C. L. \& Bakken, J. S. (2003). Successful treatment of human granulocytic ehrlichiosis in children using rifampin. Pediatrics 112, e252-e253.

Lee, H. C., Kioi, M., Han, J., Puri, R. K. \& Goodman, J. L. (2008). Anaplasma phagocytophilum-induced gene expression in both human neutrophils and HL-60 cells. Genomics 92, 144-151.

Lochary, M. E., Lockhart, P. B. \& Williams, W. T., Jr (1998). Doxycycline and staining of permanent teeth. Pediatr Infect Dis J 17, 429-431.

Munderloh, U. G., Lynch, M. J., Herron, M. J., Palmer, A. T., Kurtti, T. J., Nelson, R. D. \& Goodman, J. L. (2004). Infection of endothelial cells with Anaplasma marginale and A. phagocytophilum. Vet Microbiol 101, 53-64.
Murthy, S., Tong, H. \& Hohl, R. J. (2005). Regulation of fatty acid synthesis by farnesyl pyrophosphate. J Biol Chem 280, 41793-41804.

Parkins, M. D., Church, D. L., Jiang, X. Y. \& Gregson, D. B. (2009). Human granulocytic anaplasmosis: first reported case in Canada. Can J Infect Dis Med Microbiol 20, e100-e102.

Pusterla, N., Madigan, J. E., Asanovich, K. M., Chae, J. S., Derock, E., Leutenegger, C. M., Pusterla, J. B., Lutz, H. \& Dumler, J. S. (2000). Experimental inoculation with human granulocytic Ehrlichia agent derived from high- and low-passage cell culture in horses. $J$ Clin Microbiol 38, 1276-1278.

Rikihisa, Y. (2003). Mechanisms to create a safe haven by members of the family Anaplasmataceae. Ann N Y Acad Sci 990, 548-555.

Rikihisa, Y. (2006). Ehrlichia subversion of host innate responses. Curr Opin Microbiol 9, 95-101.

Rikihisa, Y., Zhang, Y. \& Park, J. (1995). Role of $\mathrm{Ca}^{2+}$ and calmodulin in ehrlichial infection in macrophages. Infect Immun 63, 2310-2316.

Rikihisa, Y., Zhi, N., Wormser, G. P., Wen, B., Horowitz, H. W. \& Hechemy, K. E. (1997). Ultrastructural and antigenic characterization of a granulocytic ehrlichiosis agent directly isolated and stably cultivated from a patient in New York state. J Infect Dis 175, 210-213.

Rikihisa, Y., Lin, M. \& Niu, H. (2010). Type IV secretion in the obligatory intracellular bacterium Anaplasma phagocytophilum. Cell Microbiol 12, 1213-1221.

Roux, P. P. \& Blenis, J. (2004). ERK and p38 MAPK-activated protein kinases: a family of protein kinases with diverse biological functions. Microbiol Mol Biol Rev 68, 320-344.

Sattler, I., Thiericke, R. \& Zeeck, A. (1998). The manumycin-group metabolites. Nat Prod Rep 15, 221-240.

Scharf, W., Schauer, S., Freyburger, F., Petrovec, M., Schaarschmidt-Kiener, D., Liebisch, G., Runge, M., Ganter, M., Kehl, A. \& other authors (2011). Distinct host species correlate with Anaplasma phagocytophilum ankA gene clusters. J Clin Microbiol 49, 790-796.

Slechta, L., Cialdella, J. I., Mizsak, S. A. \& Hoeksema, H. (1982). Isolation and characterization of a new antibiotic U-62162. J Antibiot (Tokyo) 35, 556-560.

Sukumaran, B., Mastronunzio, J. E., Narasimhan, S., Fankhauser, S., Uchil, P. D., Levy, R., Graham, M., Colpitts, T. M., Lesser, C. F. \& Fikrig, E. (2011). Anaplasma phagocytophilum AptA modulates Erk1/2 signalling. Cell Microbiol 13, 47-61.

Xiong, Q., Lin, M. \& Rikihisa, Y. (2009). Cholesterol-dependent Anaplasma phagocytophilum exploits the low-density lipoprotein uptake pathway. PLoS Pathog 5, e1000329.

Xu, G., Pan, J., Martin, C. \& Yeung, S.-C. (2001). Angiogenesis inhibition in the in vivo antineoplastic effect of manumycin and paclitaxel against anaplastic thyroid carcinoma. J Clin Endocrinol Metab 86, 1769-1777.

Yeung, S.-C., Xu, G., Pan, J., Christgen, M. \& Bamiagis, A. (2000). Manumycin enhances the cytotoxic effect of paclitaxel on anaplastic thyroid carcinoma cells. Cancer Res 60, 650-656.

Zhang, L., Liu, Y., Ni, D., Li, Q., Yu, Y., Yu, X. J., Wan, K., Li, D., Liang, G. \& other authors (2008). Nosocomial transmission of human granulocytic anaplasmosis in China. JAMA 300, 2263-2270. 